\title{
Identification of a new variant in the YMDD motif of the hepatitis $B$ virus polymerase gene selected during lamivudine therapy
}

\author{
HUBERT G. M. NIESTERS, ROBERT A. DE MAN*, SUZAN D. PAS, EDWIN FRIES and \\ ALBERT D. M. E. OSTERHAUS
}

Department of Virology and*Gastroenterology, University Hospital Rotterdam, Rotterdam, The Netherlands

\begin{abstract}
A new hepatitis B virus variant selected during lamivudine treatment was detected, in which the methionine (rtM204) in the so-called YMDD motif in the C domain of the catalytic site of the polymerase gene was replaced by a serine (rtM204S). This change simultaneously resulted in a tyrosine-195 into valine variant (sY195V) in the surface protein HBsAg. The detection of this YSDD variant was initially observed, after an increase of HBV DNA levels, by sequencing of amplification products from day 586. A specific RFLP assay was developed that could identify $10 \%$ of YSDD-containing variants in the virus pool, which enabled detection of this new variant virus at day 506. However, by cloning several PCR products and sequencing individual recombinant clones, the mutation was first identified at day 477 , before a significant increase of HBV DNA was observed in serum. The mutation was followed by a leucine to methionine change at position $180(\mathrm{rtL180M})$. The consequences of this mutation for disease management and diagnostic strategies are discussed.
\end{abstract}

\section{Introduction}

Potent inhibitors of hepatitis B virus (HBV) replication such as lamivudine, (-)2',3'-dideoxy-3'-thiacytidine, have recently become available. In several clinical trials, lamivudine therapy resulted in a rapid decline of serum HBV DNA levels in a majority of patients [15]. However, as with other antiviral agents, HBV variants resistant to the drug may emerge during prolonged treatment $[2,4,6-10]$ and, after cessation of therapy, HBV DNA serum levels may return to pretreatment values. Even enhanced HBV replication, resulting in a hepatitis flare, has been described [11].

Resistance to lamivudine occurs in up to $39 \%$ of patients with chronic hepatitis after 1 year of therapy. Resistance is indicated by an increase of HBV DNA levels often followed by ALT elevation. It has been attributed solely to variations in the so-called YMDD region of the polymerase gene, in which the methionine (rtM204) is replaced by either valine (rtV204) or isoleucine (rtI204). The replacement by valine is

Received 15 June 2001; revised version accepted 11 March 2002.

Corresponding author: Dr H. G. M. Niesters (e-mail: niesters@viro.fgg.eur.nl). accompanied by a change of leucine ( $r$ L180) to methionine (rtM180) [8, 10].

This paper describes the identification of a new variant in the YMDD region and discusses the possible intermediates involved in its emergence. Implications for the use of different strategies to monitor the emergence of variant viruses are discussed. The consensus rt domain numbering system as proposed by Stuyver et al. [12] has been used to describe the variants. This numbering system is genotype independent and allows a more standardised way of describing the antiviral-related changes.

\section{Materials and methods}

Patient and clinical samples

A patient of Vietnamese origin with chronic HBV infection was treated with lamivudine $150 \mathrm{mg}$ daily for a period of 756 days. The follow-up period was up to 126 days after the end of treatment (day 882). Between days 113 and 125, interferon was added (7 days with $10 \mathrm{MU}$ and 5 days with $5 \mathrm{MU}$ ) but this was withdrawn because of side-effects. All serum samples were stored frozen at $-20^{\circ} \mathrm{C}$ until use. 


\section{Measurement of HBV DNA in serum}

Where necessary, serum samples were diluted in known HBV DNA-negative serum. For the accurate measurement of HBV DNA in serum, the Digene Hybrid Capture plate assay and an in-house TaqMan assay were used $[13,14]$. The Digene assay enabled the accurate determination of HBV DNA above 200000 copies $/ \mathrm{ml}$, while the TaqMan-based assay enabled accurate determination down to 373 copies $/ \mathrm{ml}$ without a sample concentration step. Differences in HBV DNA load greater than three-fold were considered significant. All data were related to the EUROHEP HBV DNA standards [15].

\section{Sequence analysis}

A selected genomic region of the polymerase gene was amplified and sequenced with primers described previously [16]; 2- $\mu 1$ amplicons were amplified with the DYEnamic ${ }^{\mathrm{TM}}$ terminator cycle sequencing kit according to the manufacturer's protocol (Amersham Pharmacia, Roosendaal, The Netherlands). The PCR products were precipitated with $3 \mathrm{M} \mathrm{NaAc}, \mathrm{pH} 5.3$, ethanol $96 \%$ and centrifuged for $1 \mathrm{~h}$ at $2500 \mathrm{~g}$ at room temperature. Subsequently the pellets were washed with ethanol $70 \%$ and resuspended in $4 \mu \mathrm{l}$ of loading dye. The products were analysed on the ABI 373 sequencer (Applied Biosystems, Nieuwerkerk a/d IJssel). Selected PCR products were cloned into the pCRII TA vector (InVitrogen, Leek, The Netherlands). After selection of clones, a PCR reaction with the primers as above was performed directly on the recombinant colonies.

\section{RFLP analysis of YSDD}

To develop a more specific screening assay for the YSDD variant, a restriction fragment length polymorphism (RFLP) assay was developed. This detects nucleotide changes in the HBV polymerase with the restriction endonuclease SfcI (CT $\nabla$ PuPyAG; New England Biolabs, Beverly, MA, USA). The specific endonuclease site was introduced with a modified primer in the PCR (sense cac.tgt.ytg.gct.agc.tat; antisense gtt.yaa.atg.tat.acc.caa.ag), generating an amplification product of $120 \mathrm{bp}$. In case of a YSDD variant, a fragment of $105 \mathrm{bp}$ was detected by Metaphor agarose $3 \%$ gel electrophoresis with Gelstar $0.01 \%$ as intercalating dye.

\section{Results}

\section{Clinical monitoring}

Routine monitoring of patients receiving lamivudine was performed by HBV DNA quantitative assays and ALT measurements. Increased serum HBV DNA levels are indicative of resistance to lamivudine. In Fig. 1, the HBV DNA measurements and the ALT levels are documented from a chronically infected patient receiving lamivudine $150 \mathrm{mg}$ daily for a period of 756 days. ALT values were within the normal range during and after therapy, except when interferon was added. The maximal antiviral effect of lamivudine was a $5.11 \log _{10}$ HBV DNA decrease down to 10000 copies/ml at day 244. HBV DNA levels remained at $4-4.77 \log _{10}$ between days 127 and 378. A $0.5 \log _{10}$ increase of HBV DNA was observed at day 506 compared with day 441, after which levels increased to $8.31 \log _{10}$ at day 756. After the end of therapy, HBV DNA levels rose to $8.85 \log _{10}$, similar to the pre-treatment value.

\section{Sequence analysis}

Sequencing of PCR products at days 586 and 623 identified a change of rtM204S, together with an rtL180M change. At day 506, only YMDD wild-type sequences were found but day 532 both rtM204 and rtS204 were detected simultaneously. The methionine to serine change was the result of a two nucleotide change of ATG into AGT, thereby also introducing a tryptophan to valine substitution at position 195 of the HBsAg (sY195V, TGG changed to GTG). The virus was typed as HBV genotype B (ayw1 serotype according to [17]).

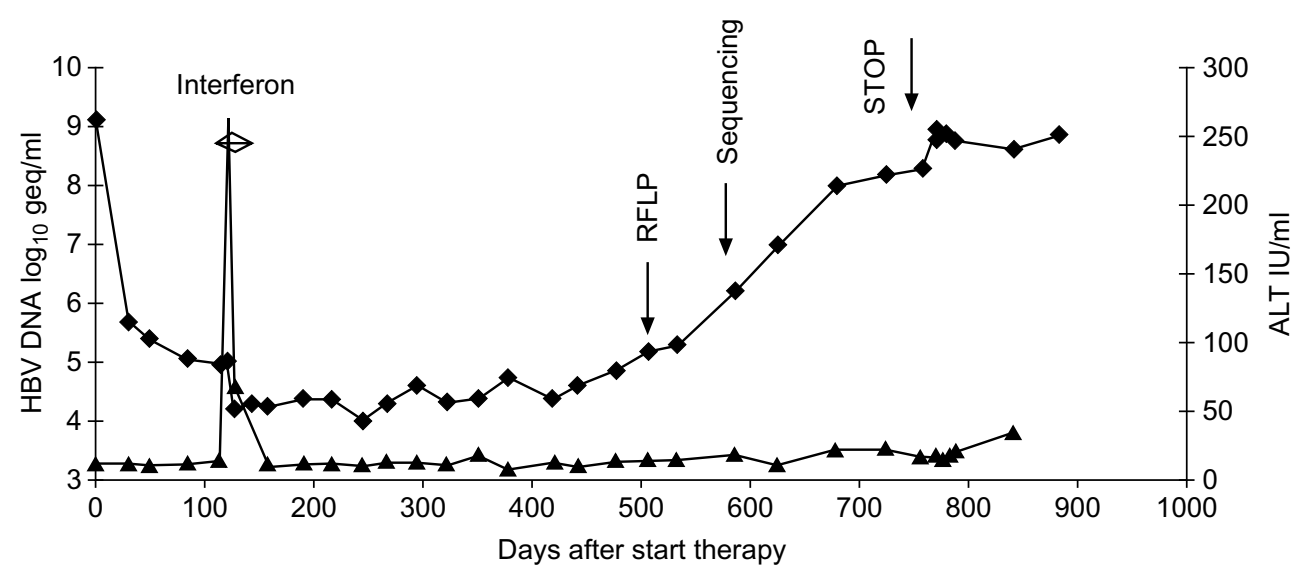

Fig. 1. HBV DNA and ALT levels in a patient with a confirmed rtS204 variant in the polymerase gene (C domain). The patient received lamivudine $150 \mathrm{mg}$ /day for 756 days. Days on which the rtS204 sequence was confirmed by analysis of PCR product or RFLP analysis are indicated by arrows. 
As sequencing of PCR products by itself is not able to detect minor variants, amplification products generated between days 477 and 532 were cloned and up to 40 independent clones per time point were sequenced. At day $477,95 \%$ of the clones sequenced contained wildtype rtM204 sequences, $2.5 \%$ of the clones contained only the rtS204 change, and $2.5 \%$ of the clones contained both rtS204 and rtM180. At day 506, 72.4\% of the clones contained wild-type rtM204 sequences, $24.1 \%$ contained the rtM180 and rtS204 changes and $3.4 \%$ contained only the rtS204 change. At day 532, these percentages were $72 \%$ for wild-type rtM204 sequences, $20 \%$ for both rtM180 and rtS204 changes, and $8 \%$ for only the rtS204 change. After day 532, $100 \%$ variant sequences $\mathrm{rtM} 180$ and $\mathrm{rtS} 204$ were detected.

\section{RFLP analysis}

To enable easy and early detection of YSDD variants, a specific RFLP assay was developed with the restriction endonuclease $S f c I$ and a modified amplification primer. The RFLP assay had a detection limit down to 1000 copies/ml, with the EUROHEP HBV DNA standard as reference, and enabled the detection of 10\% YSDDcontaining variant virus in a total $\mathrm{HBV}$ population (data not shown).

RFLP analysis of samples from selected dates during and after treatment was performed (Fig. 2). The first indication for the presence of a YSDD variant was a minor band representative of this variant obtained at day 506. At day 596, the minor $\mathrm{HBV}$ population contained wild-type sequences. At day 623 only YSDD variant sequences could be detected until the end of treatment (day 756). Wild-type sequences were already detected 13 days after the end of treatment. Surprisingly, until the last sample analysed at day 882, both YSDD and YMDD sequences were detected in equal amounts. No return to wild-type sequences only was seen.

\section{Discussion}

A new HBV variant isolated from a patient with a chronic hepatitis B virus infection has been described. In this variant, which was genotypically characterised during prolonged treatment with lamivudine, the rtM204 of the YMDD domain in the polymerase gene was changed into rtS204. The data on the rtS204 variant confirm the presence of this variant during lamivudine treatment in the patient, but do not prove an actual reduced drug susceptibility. The two previously described mutations in this domain are known as rtM204I and rtM204V, both of which result in reduced replication of HBV [18].

We and others have shown that mutations related to lamivudine arise during prolonged treatment, both in transplant patients and in other chronically infected HBV patients $[4,7,10,19,20]$. However, the incidence and patterns with which they occur may be different in the populations studied. It has been demonstrated clearly that the major mutation responsible for resistance is located in the $\mathrm{C}$ domain of the catalytic YMDD site of the polymerase gene. Furthermore, a second mutation $\mathrm{rtL} 180 \mathrm{M}$ in the $\mathrm{B}$ domain of the polymerase is often linked to the particular rtM204V change. However, this correlation has also been described recently in a limited number of patients with the rtI204 variant $[6,7]$.

There are accumulating data from molecular modelling and biochemical characterisation of variants that give more detailed insight into the mechanism of resistance of HBV and HIV-1 to lamivudine [21-23]. Steric hindrance between the side chains of the $\beta$-branched amino acids valine, isoleucine and threonine in the YMDD motif with the oxathiolane ring of lamivudine most likely accounts for the phenotypic resistance of both viruses $[22,23]$. This model may be a simplification, as in-vitro studies have shown that, for example, YADD variants of HIV-1 and Moloney murine leukemia virus are also resistant to lamivudine [21]. These authors suggest that other structural changes of the polymerase active site due to the mutation or the repositioning of the complex between the polymerase, the nucleic acid and the dNTP binding site eventually lead to steric hindrance. The described $\mathrm{rtS} 204$ variant of HBV would most likely cause changes in this replication complex according to this model.

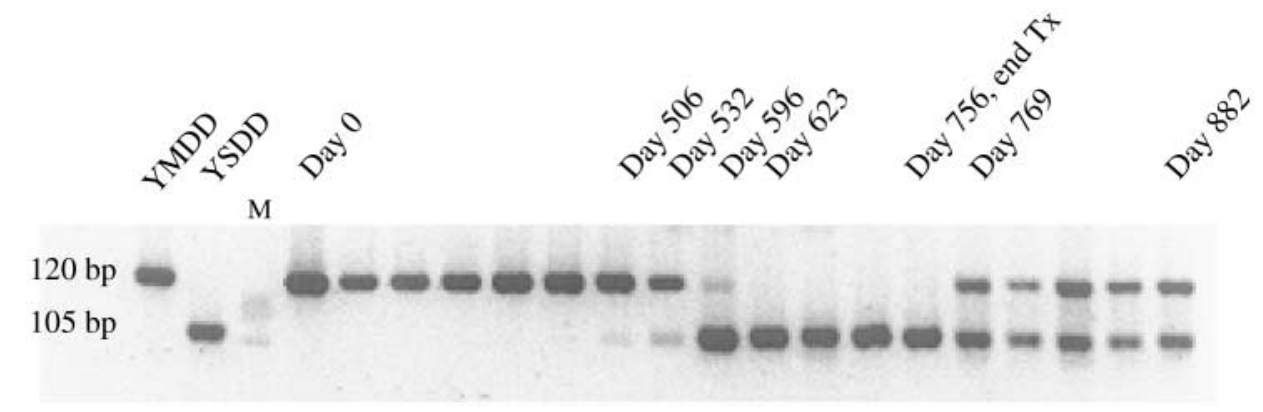

Fig. 2. RFLP analysis for the rapid detection of the rtS204 variant in the polymerase gene of HBV. PCR primers were designed to amplify a region of $120 \mathrm{bp}$. After digestion with the restriction endonuclease $S f c$, a 15 -bp fragment is removed from YSDD variants, leaving a 105-bp fragment. M, marker line (no signal). 
The YADD and YSDD mutants of HIV-1 are replication competent in vitro, but have not been observed in vivo in HIV-1-infected individuals [24]. Proviruses with reverse transcriptase containing these mutations were less infectious than wild-type virus. All reported variants related to lamivudine resistance selected in vivo so far have been caused by a single nucleotide change, whereas two mutations are required to convert the methionine codon into an alanine or serine codon. The change of methionine into serine in the HBVinfected patient in the present study is due to the change of ATG into AGT. As a working hypothesis it was assumed that a YIDD intermediate with the coding sequence ATT should precede the occurrence of the YSDD variant. However, despite screening of a large number of individual recombinant clones, this intermediate was not found.

The present study also addressed the time course of changeover from wild-type into variant sequence, as well as the events that occurred after the end of therapy. It was expected that after the end of therapy, wild-type sequences would be detected within a month without the detection of variant sequences. However, wild-type as well as variant viruses were detected in almost equal frequencies from day 13 onward until the last sample analysed 3 months later. A plausible explanation for this observation is that the replicative intermediate, known as covalently closed circular DNA (cccDNA), of HBV containing the variant sequences has established itself in the liver. As this cccDNA is not inhibited by lamivudine, the variant virus may have infected a large proportion of hepatocytes, as indicated by the high viral load of variant virus present at the end of treatment.

From a diagnostic point of view, the question arises as to how these variants can be predicted or identified as easily and quickly as possible. Assuming that the variant strains replicate less efficiently than wild-type virus, but better than the maximally suppressed virus population, accurate and well standardised viral load measurements should be indicative. Use of both a commercially available assay as well as an in-house assay demonstrated this phenomenon. Furthermore, easy-to-use methods to identify viral strains have been proposed, such as the RFLP method and the InnoLipa HBV reverse hybridisation assay $[25,26]$. Both methods seem to be sensitive, but can be used only for the identification of known variants, which is the crucial problem. We have been sequencing routinely variant populations even though this lacks sensitivity. However, it is the only method currently available which enables identification of new mutations that could be related to resistance, in combination with accurate viral DNA measurements.

In conclusion, the present study has shown for the first time the detection of a new variant of HBV selected under lamivudine treatment. This YSDD variant was also linked with the rtL180M substitution. The population of viruses present in circulation after the end of therapy contained both wild-type and variant sequences. Furthermore, these findings suggest that the use of different techniques to screen for these variants should always include sequence analysis. It is possible that more variants will be found to arise during treatment with lamivudine.

This work was partly supported by a Revolving Fund Grant from the University Hospital Rotterdam. Accession numbers for sequences are AY033072 and AY033073.

\section{References}

1. Dienstag JL, Schiff ER, Wright TL et al. Lamivudine as initial treatment for chronic hepatitis B in the United States. $N$ Engl J Med 1999; 341: 1256-1263.

2. Gauthier J, Bourne EJ, Lutz MW et al. Quantitation of hepatitis $B$ viremia and emergence of YMDD variants in patients with chronic hepatitis B treated with lamivudine. J Infect Dis 1999; 180: $1757-1762$.

3. Lai C-L, Chien R-N, Leung NW et al. A one-year trial of lamivudine for chronic hepatitis B. Asia Hepatitis Lamivudine Study Group. $N$ Engl J Med 1998; 339: 61-68.

4. Honkoop P, Niesters HG, de Man RA, Osterhaus AD, Schalm SW. Lamivudine resistance in immunocompetent chronic hepatitis B. Incidence and patterns. J Hepatol 1997; 26: 1393-1395.

5. Lai CL, Ching CK, Tung AK et al. Lamivudine is effective in suppressing hepatitis B virus DNA in Chinese hepatitis B surface antigen carriers: a placebo-controlled trial. Hepatology 1997; 25: 241-244.

6. Gutfreund KS, Williams M, George $\mathrm{R}$ et al. Genotypic succession of mutations of the hepatitis $\mathrm{B}$ virus polymerase associated with lamivudine resistance. J Hepatol 2000; 33: $469-475$.

7. Nafa S, Ahmed S, Tavan D et al. Early detection of viral resistance by determination of hepatitis B virus polymerase mutations in patients treated by lamivudine for chronic hepatitis B. Hepatology 2000; 32: 1078-1088.

8. Mutimer D, Pillay D, Cook P et al. Selection of multiresistant hepatitis B virus during sequential nucleoside-analogue therapy. $J$ Infect Dis 2000; 181: 713-716.

9. Seta T, Yokosuka O, Imazeki F, Tagawa M, Saisho H. Emergence of YMDD motif mutants of hepatitis B virus during lamivudine treatment of immunocompetent type B hepatitis patients. J Med Virol 2000; 60: 8-16.

10. Niesters HG, Honkoop P, Haagsma EB, de Man RA, Schalm $\mathrm{SW}$, Osterhaus ADME. Identification of more than one mutation in the hepatitis $\mathrm{B}$ virus polymerase gene arising during prolonged lamivudine treatment. J Infect Dis 1998; 177: $1382-1385$.

11. Honkoop P, de Man RA, Heijtink RA, Schalm SW. Hepatitis B reactivation after lamivudine. Lancet 1995; 346: 1156-1157.

12. Stuyver LJ, Locarnini, SA, Lok A et al. Nomenclature for antiviral-resistant human hepatitis B virus mutations in the polymerase region. Hepatology 2001; 33: 751-757.

13. Pas SD, Fries E, de Man RA, Osterhaus ADME, Niesters HGM. Development of a quantitative real-time detection assay for hepatitis B virus DNA and comparison with two commercial assays. J Clin Microbiol 2000; 38: 2897-2901.

14. Niesters HGM, Krajden M, Cork L et al. A multicenter study evaluation of the Digene Hybrid Capture II signal amplification technique for detection of hepatitis B virus DNA in serum samples and testing of EUROHEP standards. J Clin Microbiol 2000; 38: 2150-2155.

15. Heermann K-H, Gerlich WH, Chudy M, Schaefer S, Thomssen $\mathrm{R}$ and the Eurohep Pathobiology Group. Quantitative detection of hepatitis B virus DNA in two international reference plasma preparations. J Clin Microbiol 1999; 37: 68-73.

16. Osterhaus $\mathrm{AD}$, Vos $\mathrm{MC}$, Balk $\mathrm{AH}$ et al. Transmission of hepatitis $\mathrm{B}$ virus among heart transplant recipients during endomyocardial biopsy procedures. J Heart Lung Transplant 1998; 17: 158-166. 
17. Norder H, Couroucé A-M, Magnius LO. Molecular basis of hepatitis B virus serotype variations within the four major subtypes. J Gen Virol 1992; 73: 3141-3145.

18. Melegari M, Scaglioni PP, Wands JR. Hepatitis B virus mutants associated with 3TC and famciclovir administration are replication defective. Hepatology 1998; 27: 628-633.

19. Puchhammer-Stöckl E, Mandl CW, Kletzmayr J et al. Monitoring the virus load can predict the emergence of drug-resistant hepatitis B virus strains in renal transplantation patients during lamivudine therapy. J Infect Dis 2000; 181: 2063-2066.

20. Mutimer D. Hepatitis B virus antiviral drug resistance: from the laboratory to the patient. Antivir Ther 1998; 3: 243-246.

21. Boyer PL, Gao H-Q, Clark PK, Sarafianos SG, Arnold E, Hughes SH. YADD mutants of human immunodeficiency virus type 1 and Moloney murine leukemia virus reverse transcriptase are resistant to lamivudine triphosphate (3TCTP) in vitro. $J$ Virol 2001; 75: 6321-6328.

22. Das $\mathrm{K}$, Xiong $\mathrm{X}$, Yang $\mathrm{H}$ et al. Molecular modeling and biochemical characterization reveal the mechanism of hepatitis
$B$ virus polymerase resistance to lamivudine (3TC) and emtricitabine (FTC). J Virol 2001; 75: 4771-4779.

23. Sarafianos SG, Das K, Clark AD et al. Lamivudine (3TC) resistance in HIV-1 reverse transcriptase involves steric hindrance with beta-branched amino acids. Proc Natl Acad Sci USA 1999; 96: 10027-10032.

24. Wakefield JK, Jablonski SA, Morrow CD. In vitro enzymatic activity of human immunodeficiency virus type 1 reverse transcriptase mutants in the highly conserved YMDD amino acid motif correlates with the infectious potential of the proviral genome. J Virol 1992; 66: 6806-6812.

25. Stuyver L, Van Geyt C, De Gendt S et al. Line probe assay for monitoring drug resistance in hepatitis $\mathrm{B}$ virus-infected patients during antiviral therapy. $J$ Clin Microbiol 2000; 38: $702-707$.

26. Allen MI, Gauthier J, Deslauriers M et al. Two sensitive PCRbased methods for detection of hepatitis B virus variants associated with reduced susceptibility to lamivudine. J Clin Microbiol 1999; 37: 3338-3347. 